A N N A L E S Annales de Bretagne et des Pays de l'Ouest

\title{
Association des Amis des Archives Historiques du Diocèse de Rennes, Dol et Saint-Malo, Cartulaire de Redon
}

Bernard Merdrignac

\section{(2) OpenEdition}

Journals

Édition électronique

URL : http://journals.openedition.org/abpo/1156

DOI : $10.4000 / a b p o .1156$

ISBN : 978-2-7535-1497-3

ISSN : 2108-6443

Éditeur

Presses universitaires de Rennes

\section{Édition imprimée}

Date de publication : 20 mars 2005

Pagination : 175-176

ISBN : 978-2-7535-0125-6

ISSN : 0399-0826

\section{Référence électronique}

Bernard Merdrignac, "Association des Amis des Archives Historiques du Diocèse de Rennes, Dol et Saint-Malo, Cartulaire de Redon ", Annales de Bretagne et des Pays de l'Ouest [En ligne], 112-1 | 2005, mis en ligne le 20 mars 2007, consulté le 23 septembre 2020. URL : http://journals.openedition.org/abpo/ 1156 ; DOI : https://doi.org/10.4000/abpo.1156 
explique que la carrière de beaucoup de chanoines soit passée par la cour ducale et par l'université. Aussi l'étude de ces institutions n'a-t-elle pas encore livré tous ses enseignements.

Bernard MERDRIGNAC

Association des Amis des Archives Historiques du Diocèse de Rennes, Dol et SaintMalo, Cartulaire de Redon - II, AHID, Rennes, 2004.

Le succès - largement mérité - de l'édition en fac-similé du Cartulaire de Redon a dépassé les espérances des Amis des Archives Historiques du Diocèse de Rennes puisque l'ouvrage tiré à près de 3500 exemplaires, voici déjà six ans, est à présent totalement épuisé. Ce " beau livre " prenait place dans les bibliothèques aux côtés de la publication, en 1863 (selon des normes éditoriales aujourd'hui dépassées) par Aurélien de Courson, de cette source essentielle de l'histoire de la Bretagne du haut Moyen Âge. Beaucoup de régions la lui envient, à juste titre : il n'existe pas dans tout le grand Ouest de document comparable en ce qui concerne l'époque carolingienne. Le document original était enfin aisément accessible et il était dorénavant aisé pour les historiens de comparer celuici à l'édition de Courson dont l'Index, en dépit de ses graves imperfections déjà dénoncées en leur temps par le savant celtisant Joseph Loth, demeurait le seul instrument de travail disponible.

C'est pourquoi l'Association récidive en proposant un volume complémentaire réservé à l'usage des détenteurs du premier tome. L'Index generalis (66 pages) réalisé par Bernard Tanguy, chercheur CNRS au Centre de Recherches Bretonnes et Celtiques de l'Université de Bretagne Occidentale répertorie minutieusement plus de trois mille toponymes et anthroponymes mentionnés dans le Cartulaire. Ce travail exemplaire constitue une mine pour l'étude de l'onomastique et de la langue bretonne durant le haut Moyen Âge. L'indication des folios du manuscrit est suivie de la pagination dans l'édition de Courson et, le cas échéant, afin de faciliter l'identification des personnes, de la datation des actes proposée par Hubert Guillotel dans le volume I.

L'ouvrage est en effet dédié à la mémoire de cet historien disparu brutalement en 2004. Comme le rappelle Georges Provost, président de l'Association des Amis des Archives Historiques du Diocèse de Rennes, Dol et Saint-Malo, celuici s'est attaché durant les trois dernières décennies, avec l'acribie qui était sa marque de fabrique, à reconstituer la teneur des 42 folios disparus depuis le $\mathrm{XVII}^{\mathrm{e}}$ siècle (f ${ }^{\circ} 9$ à 50 ) et du " second cartulaire " dont ne subsistent que 2 folios conservés à la mairie de Redon et 4 folios parvenus, à la suite de diverses vicissitudes, au cabinet des médailles de la BNF (Nouv. acq. lat. 2208). Ces douze pages sont reproduites en fac-similés au cœur du présent volume. Jean-Pierre Brunterc'h, conservateur en chef à la BNF a pris le relais du savant disparu en proposant une reconstitution de la partie perdue du Cartulaire de Redon et en mettant en forme, avec délicatesse, les recherches de son collègue et ami sur le deuxième cartulaire. En prémices aux travaux que laisse désormais espérer l'édition de ces deux tomes, J.-P. Brunterc'h donne ici l'édition critique - d'après des copies d'érudits du XVII ${ }^{\text {e }}$ siècle - d'un acte d'Érispoé que contenait la partie perdue du Cartulaire ( $\left.f^{\circ} 31\right)$ et qu'Hubert Guillotel, à la suite de Ferdinand Lot, datait du 10 mars 851, ce qui suppose qu'il a immédiatement été établi (en même temps que deux autres chartes) à l'annonce du décès de Nominoé. 
Pour compléter l'ouvrage, Alain Duval, Hélène Guicharnaud et Sandrine Pagès-Camagna du "Centre de recherche et de restauration des musées de France " ont réalisé une étude scientifique des enluminures et des encres, par examens visuels (à l'œil nu et à la loupe binoculaire) puis analyse élémentaire (par rayons $\mathrm{X}$ induits par protons - PIXE) et analyse structurale (par microspectrométrie Raman). Le minium (pour les lettrines orangées), le rouge-vermillon, le vert-de-gris et le lapis-lazuli (plus rare, parce que très onéreux) sont souvent juxtaposés deux par deux mais pratiquement jamais superposés afin d'obtenir une ornementation plus complexe. N'y a-t-il pas là une trace d'archaïsme, demandait $\mathrm{H}$. Guillotel en présentant le manuscrit dans le premier volume? Il déduisait de la décoration des lettrines une confirmation de l'influence du scriptorium du Mont-Saint-Michel sur celui de Redon.

Signalons pour clore ce compte rendu que l'Association des Amis des Archives Historiques du Diocèse de Rennes, Dol et Saint-Malo, qui fait décidément montre d'un dynamisme incoercible, annonce pour ce premier semestre 2005, l'édition d'un CD Rom reprenant l'intégralité des fac-similés et des textes des deux volumes du Cartulaire. Nul doute que ce nouvel outil de travail - doté bien entendu de liens destinés à faciliter les recherches - rendra bien des services dans la perspective d'une étape à venir du chantier, évoquée ici par G. Provost, comme l'avait déjà fait en 1998 Jacques Charpy, son prédécesseur à la présidence de l'Association. Une édition renouvelée du cartulaire, avec traduction des textes latins et discussion critique du contenu de chaque acte, s'impose à présent. Mais c'est une entreprise de longue haleine qui, dans les conditions actuelles, impliquerait un travail d'équipe et une approche pluridisciplinaire.

Bernard MERDRIGNAC

VINCENT, Catherine, Fiat Lux. Lumière et luminaires dans la vie religieuse du XIII au Xve siècle, Paris, Cerf, 2004.

Fiat Lux, dit Dieu, « ...et la lumière fut! », selon la Genèse (I, 3). Tout autant que le récit biblique de la Création, l'expression latine évoquera peut-être aujourd'hui pour certains lecteurs l'enseigne de l'agence de Nestor Burma. Le détective privé imaginé par Léo Mallet connaît en effet un regain de célébrité grâce à une série télévisée à succès. Ce rapprochement malicieux n'est peut-être pas aussi incongru qu'il pourrait le paraitre de prime abord. Il donne un relief inattendu, mais somme toute assez éclairant, au titre de la minutieuse enquête d'anthropologie historique conduite par Catherine Vincent. L'ouvrage est issu de la thèse d'habilitation consacrée par celle-ci aux pratiques religieuses associées aux luminaires durant les derniers siècles du Moyen Âge. Jusque très récemment, un tel sujet ne retenait guère l'intérêt des historiens. Au mieux, de rares études accordaient, avec une ironie condescendante, quelques digressions amusées aux " querelles de bout de chandelles " rencontrées au hasard des sources. La relation entre les spéculations théologiques et mystiques à partir des métaphores lumineuses de l'Écriture Sainte et les humbles pratiques du clergé et des simples fidèles n'avait en effet jamais retenu systématiquement l'attention des historiens. Dans ces conditions, la moindre des gageures n'était pas, pour l'auteur de tracer sa route à travers une documentation abondante, mais disparate et dispersée. Collections canoniques, traités liturgiques (tel le fameux Pontifical de Guillaume Durand, $\uparrow 1296)$, coutumiers monastiques de Cluny ou de Cîteaux, 